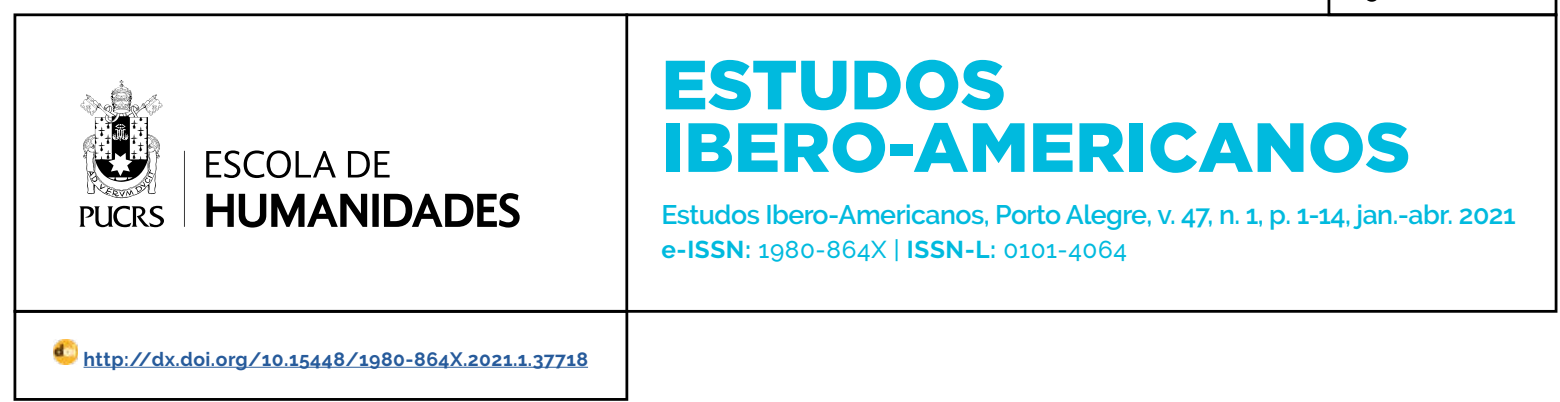

DOSSIÊ: HISTÓRIA DAS MULHERES, DAS RELAÇÕES DE GÊNERO E DAS SEXUALIDADES DISSIDENTES - VOL. 47, N. 1

\title{
Feminismo, vegetarianismo e antivivisseccionismo em Maria Lacerda de Moura
}

\author{
Feminism, vegetarianism, and antivivisectionism in Maria Lacerda de Moura \\ Feminismo, vegetarianismo e antivivisseccionismo en Maria Lacerda de Moura
}

\section{Patrícia Lessa ${ }^{1}$ \\ orcid.org/0000-0002-8942-1308 \\ patricialessa13@gmail.com}

\section{Cláudia Maia ${ }^{2}$}

orcid.org/000-0002-8358-8940

claudia.maia@unimontes.br

Recebido em: 16/04/2020.

Aprovado em: 18/12/2020.

Publicado em: 30/04 2021
Resumo: A História das mulheres tem evidenciado as múltiplas experiências delas, no passado, e o caráter plural e multifacetado de suas lutas. No final do século XIX e início do XX, as mulheres, feministas ou não, aderiram a diferentes pautas que iam além da reivindicação por direitos femininos, tais como o republicanismo e o abolicionismo. A empatia pelos animais não humanos, vitimas de experimentos científicos e usados como cobaias pela indústria, nesse periodo, também levou muitas delas a se tornarem vegetarianas e a aderirem à luta antivivisseccionista; no Brasil, a intelectual feminista e anarquista Maria Lacerda de Moura foi uma dessas mulheres. Nesse artigo buscamos entender suas posições e sua relação com essas lutas, a partir da análise da sua obra Civilização Tronco de Escravos, publicada em 1931.

Palavras-chave: Maria Lacerda de Moura. Feminismo. Vegetarianismo. Antivivisseccionismo.

Abstract: The History of women has highlighted the multiple experiences of women in the past, but also the plural and multifaceted character of their struggles. At the end of the 19th century and the beginning of the 20th the women, feminist or not, adhered to different agendas that went beyond the claim for women's rights such as republicanism and abolitionism. The empathy for non-human animals, victims of scientific experiments and used as guinea pigs by the industry, during this period, also led many of them to become vegetarians and join to the antivivisectionist struggle; in Brazil, feminist and anarchist intellectual Maria Lacerda de Moura was one of these women. In this article, we seek to understand her positions and her relationship with these struggles from analyze of her work Civilização Tronco de Escravos, published in 1931.

Keywords: Maria Lacerda de Moura. Feminism. Vegetarianismo. Antivivisectionism.

Resumen: La Historia de las mujeres deja en evidencia sus múltiples experiencias del pasado, asi como el carácter plural y multifácetico de sus luchas. A finales del siglo XIX e inicios del XX, las mujeres, feministas o no adhirieron a diferentes pautas que iban más allá de la reivindicación por derechos femeninos tales como el republicanismo y el abolicionismo. La empatía por los animales no humanos victimas de experimentos científicos y usados como cobayos por la industria, generó que muchas mujeres se hicieran vegetarianas y adhririeran a la lucha antiviviseccionista. En Brasil, la intelectual feminista y anarquista Maria Lacerda de Moura fue una de ellas. En este artículo, buscamos entender sus posiciones y su relación con esas luchas a partir del análisis de su obra Civilización Tronco de Esclavos, publicada en 1931.

Palabras-clave: Maria Lacerda de Moura. Feminismo. Vegetarianismo. Antiviviseccionismo 


\section{Introdução}

Maria Lacerda de Moura foi uma mulher que exerceu grande influência no pensamento feminista, social e de esquerda no Brasil nas primeiras décadas do século XX. Ela nasceu em 1887 em Manhuaçu, Minas Gerais e, aos quatro anos de idade mudou-se com seus pais para Barbacena, onde, mais tarde, se formou como normalista e exerceu a docência. Teria sido mais uma dentre muitas professoras mineiras conhecidas por sua dedicação à familia, à escola e aos alunos, não fosse o deslocamento radical feito por ela em sua vida e em seu pensamento. No início dos anos de 1920 separou-se do marido e mudou-se para São Paulo onde iniciou a luta pela emancipação feminina - ao lado de Bertha Lutz, de quem logo se distanciou - e passou a fazer parte de círculos de intelectuais. Já no final dessa década, ela se aproximou dos anarquistas e passou a denunciar em seus escritos o autoritarismo do Estado e da Igreja, o avanço de ideais fascistas, a tendência à militarização do Estado e o serviço militar obrigatório para homens e mulheres, tornando-se grande inspiradora dos movimentos antifascistas no Brasil, conforme noticiou o jornal A Manhã (1928). Assim, ela se tornou conhecida pelos seus livros, seus artigos para jornais e suas conferências, que fizeram dela uma das vozes mais peculiares do feminismo naquele momento histórico.

No início do século $X X$ o mundo estava em alvoroço, diante de uma industrialização mecanizada, com uma produção de armamentos em alta, fruto da parceria ciência-empresa-política, e, com o avanço do nazifascismo, cresciam os abismos entre etnias-raças, gêneros e classes sociais. Essas forças destrutivas geraram uma forte reação anarquista e socialista, polarizando o mundo. Dentre os grupos de mulheres socialistas, anarquistas e, mesmo, as mulheres liberais, res- surgiu o movimento feminista, que trazia consigo diferentes perspectivas e pautas. As questões das mulheres eram agregadas às lutas de classe, de raça e, um pouco menos debatidas, as lutas antiespecistas. Por especismo se entende a diferença que se faz por espécie, ou seja, a espécie humana se autoproclamando superior às demais e, em função disso, se considerando no direito de explorar, escravizar e dizimar as demais espécies, por ela consideradas inferiores. No século XXI o debate ampliou-se, sobretudo com o veganismo ${ }^{3}$ e com a adoção dos termos animal humano e animal não humano para ampliar a visão de que participamos também, do reino animal, ressalvadas as diferenças entre as espécies. Mas foi ainda no século XIX que muitas feministas começaram a se assumir vegetarianas, sobretudo em função do combate à vivissecção, ${ }^{4}$ que estava em alta com o darwinismo e os avanços das ciências médicas. Em Pitágoras já se propunha a dieta vegetariana. Ao longo da história humana e nas diferentes geografias o vegetarianismo é, desde há muito, uma prática conhecida. Porém, um movimento de repercussão internacional pode ser percebido entre as feministas e os(as) anarquistas do século XIX, como veremos. No Brasil, Maria Lacerda de Moura foi uma das feministas que aderiu à luta antiespecista, passando a denunciar em seus escritos também a vivissecção e os experimentos com animais.

Maria Lacerda ficou conhecida, especialmente, pelos estudos de Miriam Lifchitz Moreira Leite, como importante educadora e feminista que trabalhou pela inserção das mulheres nos bancos escolares e, também, pelos estudos de Margareth Rago que ressaltou suas lutas anarquistas contra o fascismo e em prol das mulheres. Mas, em sua extensa obra, ela tratou de uma ampla variedade de temas, muitos deles ainda não elencados nos

\footnotetext{
3 Veganismo é um ativismo social em defesa da vida das outras espécies animais. É uma prática social que está muito além da alimentação (não se alimentar de produtos derivados de animais, como por exemplo, o cuidado em substituir as cápsulas de medicamentos homeopáticos por cápsulas de algas ao invés de gelatina, que é de origem animal). As pessoas veganas procuram não utilizar roupas e acessórios feitos com produto de origem animal, além disso, graças a luta vegana os produtos livres de testes com animais e produtos veganos possuem selos de identificação.

4 É a prática de utilizar um animal vivo na ciência e na indústria. O uso dos animais vivos é, em sua maioria, para realizar testes laboratoriais (testes com drogas, cosméticos, produtos de limpeza, de higiene etc.), nas práticas médicas (treinamento cirúrgico, transplante de órgãos etc.), experimentos de psicologia (privação materna etc.), usam-se animais vivos ainda hoje na ciência e na indústria em grande escala. A palavra vivissecção significa cortar o animal vivo, mas, hoje ela agrega outras manipulações como inclusão de tumor maligno em um organismo saudável, uso de fermentas e métodos de contenção etc.
} 
estudos que a contemplam, ${ }^{5}$ como, por exemplo, suas posições em favor das lutas antivivisseccionistas, ${ }^{6}$ um importante avanço no campo dos atuais estudos animalistas. Essas aprofundadas reflexões vão muito além da discussão acerca da alimentação, do veganismo ou não veganismo, pois abordam as leis, as artes e as formas de convivência interespécies.

Assim sendo, buscamos analisar, nesse artigo, as ideias dessa professora mineira acerca do feminismo, do vegetarianismo e do antivivisseccionismo na obra Civilização tronco de escravos, publicada em 1931 pela editora Civilização Brasileira. O livro consiste em 15 capítulos curtos nos quais a autora aborda várias temáticas, mas todas problematizando em tom de denúncia o modelo de civilização burguesa cristã baseado na hipocrisia, por um lado, e, por outro, na ciência a serviço da guerra e do capitalismo. Por ocasião do lançamento do livro, o jornal Correio da Manhã publicou o seguinte comentário: "Libello destemido contra os vícios da sociedade, as mentiras convencionadas, as injustiças, hipocrisias e violências que fundamentam a vida moderna".?

\section{As feministas do final do século XIX e início do XX}

No bojo da Revolução Francesa, algumas mulheres abriram as portas para a reivindicação dos seus direitos: Olympe de Gouges (1748-1793), na França, e Mary Wollstonecraft (1759-1797) no Reino Unido, tiveram seus nomes registrados na história. Além delas, muitas ilustres desconhecidas lutaram também pelos direitos das mulheres. Mas foi no final do século XIX e início do XX que nasceu uma revolução feminista sem precedentes. Foram muitas lutas, embates e conquistas. No início do século XX, o movimento sufragista marcou a historiografia e imortalizou alguns nomes de mulheres que lutaram pelo direito ao voto, ao exercício da cidadania e por melhores condições de trabalho, como por exemplo Bertha Lutz (1894-1976), Alicia Moreau de Justo (1885-1986) e Emmeline Pankhurst (1858-1928). A luta sufragista marcou o que ficou conhecido como a primeira onda ou primeira vaga feminista. ${ }^{8}$ Foi nos embates das relações entre público e privado que as mulheres foram ocupando os espaços e, então, vimos nascer cientistas, educadoras e livre pensadoras. Mulheres como Marie Curie, laureada com o prêmio Nobel de Física e Quimica em 1903 e 1911. Em 1932 as mulheres brasileiras conquistaram o direito ao voto mesmo antes de países como a França, onde feministas como Simone de Beauvoir, autora da obra $O$ Segundo Sexo, e Monique Wittig, com Le Corps Lesbien, posteriormente escreveram esses livros, considerados clássicos.

Não foi por acaso que o final do século XIX e o início do XX foram marcados pela emergência da voz feminista. Os discursos da medicina e da biologia tentavam comprovar, cientificamente, a inferioridade das mulheres através da ideologia da natureza feminina e da elaboração dos fundamentos científicos da teoria da incapacidade inata delas. As disciplinas em curso eram, especialmente, a obstetrícia, a ginecologia, a biologia, a sociologia, a psicologia e a antropologia, todas empenhadas na elaboração desses fundamentos. Os cientistas, a exemplo de Cesare Lombroso e de Pierre Broca, utilizavam a teoria da incapacidade ou da fragilidade inata para desqualificar as mulheres de sua própria raça e classe e limitá-las ao reduto doméstico, pois o mesmo argumento não servia para desqualificar as mulheres da classe operária que eram forçadas a trabalhar longas jornadas. Da influência da Antropometria surge a Craniometria (medição do crânio), que teve como um dos mentores intelectuais o francês Pierre Broca (1824-1880).

\footnotetext{
Cf. LEITE, 1984; RAGO, 2007

Luta das pessoas contrárias ao uso de cobaias animais (não voluntárias, mas, forçadas) na ciência e na indústria.

CORREIO DA MANHÃ. Rio de Janeiro: Civilização Brasileira Editora, 13 set. 1931. p. 2.

8 A noção de ondas para se referir a momentos de efervescência do feminismo foi criticada por Joana Maria Pedro (2011, p. 271). Conforme essa autora "pensar o feminismo a partir de diferentes ondas, reforça a ideia da existência de centros irradiadores e suas margens" e desconsidera os distintos momentos dos movimentos de mulheres em contextos como de alguns países latino-americanos, em que os momentos de efervescência da luta das mulheres não necessariamente são concomitantes ou derivaram dos do centro como nos países do Norte. Apesar de concordar com a autora, optamos por usar o termo "onda" por ser conhecido e considerar que atende a história do feminismo brasileiro.
} 
A craniometria influenciou as ciências do século XIX e foi um esteio para a invenção cientifica da tese da superioridade masculina, branca e da classe média e alta europeia (HUBBARD, 1993; LESSA, 2014). Mas as mulheres não aceitaram isso passivamente. Foram às ruas e construiram os pilares do movimento feminista internacional.

Foi neste contexto, de uma ciência empenhada em desqualificar as mulheres e jogá-las no reduto doméstico, que aconteceu o encontro e o desencontro de duas feministas brasileiras: Maria Lacerda de Moura (1887-1945) e Bertha Maria Júlia Lutz (1894-1976). A primeira foi uma educadora mineira, escritora, anarquista e livre pensadora. A segunda, nascida em São Paulo, graduada em Biologia pela Universidade de Paris 4 - Sorbonne - e, mais adiante, em Direito pela Faculdade do Rio de Janeiro. Bertha foi a segunda mulher no Brasil a ingressar na carreira pública via concurso para atuar como secretária no Museu Nacional do Rio de Janeiro. ${ }^{9}$ Ainda em 1919 fundou a Liga para a Emancipação Intelectual da Mulher e convidou Maria Lacerda de Moura para trabalharem pela educação das mulheres. Em 1922 representou as brasileiras na Assembleia Geral da Liga das Mulheres Eleitoras, nos Estados Unidos, onde foi eleita vice-presidente da Sociedade Pan-Americana. Ao regressar, criou a Federação Brasileira para o Progresso Feminino, que substituiu a liga, criada em 1919, para encaminhar a luta pela extensão do direito de voto às mulheres (LESSA, 2014. 2020). Entre 1921 e 1922 Maria Lacerda presidiu a Federação Internacional Feminina e sugeriu, pela primeira vez, a criação da disciplina de História da Mulher nas escolas normalistas, o que veio a acontecer décadas depois.

A parceria entre as duas feministas não duraria muito tempo. Maria Lacerda rompeu com as mulheres da Federação por entender que as suas lutas não se estendiam às operárias, mulheres da classe trabalhadora, que não tinham acesso ao estudo e que, portanto, as lutas sufragistas não as atingiam. Em sua autobiografia ela relata a ruptura, diz:

\section{Em 1921 vim para São Paulo.}

Um grupo de senhoras de Santos e São Paulo me veio procurar para fundar a "Federação Internacional Feminina". Dois anos de experiências diárias me fizeram recuar para "todo o sempre" de associações femininas (MOURA, 2005, p. 39)

O texto autobiográfico foi publicado em agosto de 1929 no jornal operário O Combate. Maria Lacerda já estava vivendo em uma comunidade rural em Guararema, entre libertários e desertores da primeira Guerra Mundial. Ela estava empenhada na luta antifascista e em algumas das frentes anarquistas, tais como o amor livre e a luta operária. No ano seguinte, em 1930, ela recebeu uma carta da Sr. ${ }^{\text {a }}$ Sergia F. Vidal, Presidente da "União Cívica Radical" de La Plata, então província de Buenos Aires, na Argentina que pretendia conseguir o contato de Bertha Lutz através de Maria Lacerda. Na resposta à carta a escritora mineira foi bem mais contundente e deixou explicitas suas diferenças em relação às feministas burguesas. A carta resposta, escrita em julho de 1930, foi publicada no livro Civilização, tronco de escravos, onde ela escreveu:

Peço-lhe perdão pelo fato de não poder ajudá- la e à União Cívica Radical nessa "campanha de moralidade".

Nem mesmo me dirijo, conforme sua solicitação, a Sr. ${ }^{a}$ Bertha Lutz, representante ilustre e digna da Liga Internacional de Mulheres Ibérica e Hispano Americanas, instalada em New York com sucursais em toda parte, nos países civilizados.

Não, minha Senhora. Não posso proceder contra a minha consciência.

Não sou, absolutamente, radical em cousa alguma, nem faço parte de nenhuma associação de mulheres burguesas e, consequentemente, reacionárias (MOURA, 1931, p. 205-206).

9 Importante ressaltar que ela acionou a justiça para garantir o direito a realizar o concurso público, pois, na época era vedada a participação das mulheres, porém, já havia o precedente quando, em 1918, a Maria José de Castro Rebello Mendes prestou concurso público e ficou em primeiro lugar vindo a ser a primeira diplomata brasileira e a primeira mulher a ingressar na carreira pública via concurso. O código civil de 1916 estabelecia a incapacidade das mulheres casadas ao lado de menores, loucos e indigenas; conforme a legislação elas não eram consideradas "indivíduo". Um decreto dos Correios de 1922 passava a considerar como individuos as "moças dos Correios", o que evidencia a maior possibilidade de mulheres solteiras como Bertha conseguirem, não sem luta, a ingressarem no serviço público (LESSA, 2020). O Museu Nacional, onde Bertha ingressou como secretária e, posteriormente atuou como cientista, foi vítima de um incêndio que destruiu grande parte do acervo e do prédio histórico no dia 2 de setembro de 2018. Para um estudo mais aprofundado sobre Bertha Lutz, consultar: SOIHET, Rachel. O feminismo tático de Bertha Lutz. Florianópolis: Editora das Mulheres; EDUNISC, 2006. 
Na resposta ela deixa clara a sua ruptura com as lutas das mulheres burguesas, mais especificamente com as das sufragistas, pois o direito ao voto não estava na agenda da luta de classes, e mais urgentes eram as questões da redução da jornada de trabalho e as salariais. Cumpre destacar que as lutas libertárias abordavam a questão dos papéis de gênero na sociedade da época, cujas posições eram profundamente desiguais. Por conseguinte, as anarquistas não queriam ser associadas às feministas burguesas, por considerarem suas lutas limitadas às classes privilegiadas e muito distantes das necessidades da classe operária. Margareth Rago, ao pesquisar o pensamento libertário, nos esclarece:

Não raras vezes as "anarquistas históricas", como a própria Luce Fabbri, não se consideravam feministas, entendendo com esse termo aquelas que lutavam pelo direito feminino ao voto. No entanto, nem por isso deixaram de se preocupar com as questões femininas, tendo em vista a liberação das mulheres das inúmeras sujeições e exclusões cotidianas, o que as torna então feministas, a exemplo de Maria Lacerda de Moura (RAGO, 2007, p. 9).

Assim como Rago, consideramos a luta de Maria Lacerda feminista, embora ela tenha deixado de utilizar o termo - já que ele passou a ser sinônimo do sufragismo - após dois anos de trabalho ao lado das mulheres da Federação. Ela não gostava de definições e nem mesmo se autodenominava libertária, embora suas batalhas no campo da emancipação sejam típicas dos escritos anarquistas da época, escritos esses que constituíram uma obra hoje interpretada como feminista libertária.

Um dos pontos nevrálgicos da obra lacerdiana para as lutas feministas é a forma como ela percebia e combatia a prostituição. Vale lembrar que, naquela época, a ciência patologizava, as politicas sociais higienizavam e o direito criminalizava a prostituição; mas, por outro lado, os bordéis franceses ganhavam fama internacional e eram disputadissimos pelos mesmos senhores que condenavam a prostituição de rua ou a baixa prostituição. Criado em 1889, o Moulin Rouge, situado no coração de Montmartre, bairro boêmio de Paris, na França, logo virou paradig- mático. O Le Chat Noir foi outro famoso cabaré francês, criado em 1881 e considerado luxuoso, frequentado por políticos, médicos, cientistas, escritores, artistas e figuras ilustres, que buscavam na região da boemia francesa as prostitutas de luxo. Esse modelo foi sendo adotado mundo afora, e, no Brasil, não foi diferente. Sobre este tópico escreveu Margareth:

Em São Paulo, os médicos e os policiais tinham começado a perceber as sexualidades perigosas como uma grande ameaça, desde o final do século 19, com a chegada dos enormes contingentes de imigrantes europeus, no porto de Santos. Dentre estes, desembarcavam indesejáveis de todos os tipos, como notificavam os inspetores de polícia: anarquistas italianos, portugueses e espanhóis; prostitutas e cafetinas francesas e portuguesas; cáftens eslavos acompanhados de polacas voluntárias ou forçadas, as chamadas escravas brancas, destinadas a suprir o próspero mercado da prostituição nos trópicos (RAGO, 2005, p. 97).

O mesmo ocorria no Rio de Janeiro, que era a capital naquela época. Em 1830 com a criação da Academia Imperial de Medicina e da Faculdade de Medicina, os cientistas se organizaram e avolumavam-se publicações sobre os problemas que afligiam a cidade, vista como espaço de proliferação de doenças, portanto passivel de uma política higienista. No contexto do estudo das doenças, as ditas "perversões sexuais" ganharam foco, dentre elas as sexualidades ilegitimas. A homossexualidade, a masturbação, a abstinência sexual e a prostituição são temas do domínio médico científico, em ascensão à época. Mais adiante, a criação da Sociedade Eugênica para melhorar e purificar a raça, em 1918, colaborou para a "limpeza", para a exclusão ou mesmo para o extermínio dos indesejáveis. Os médicos passaram a cumprir a função, que antes era dos padres, de conselheiros da população. E, com isso, o poder médico passou a definir os modernos códigos de conduta (RAGO, 2005). Nesse periodo, também a abstêmia sexual, especialmente a feminina, passa a ser tema do conhecimento médico, por não aderir a uma prática sexual sadia e não colocar o corpo a serviço da reprodução, também a mulher celibatária (solteirona) passa a ser vista como um sujeito deficitário e indesejado (MAIA; LESSA, 2015). 
Em sua obra Renovação, datada de 1919, Maria Lacerda de Moura aborda o tema da prostituição, retomado em outros textos como no livro Han Ryner e o amor plural de 1933. Naquele livro ela adverte sobre como os envolvimentos sexuais remunerados são depreciativos para a mulher e, praticamente, sem consequências aos homens, sempre protegidos pela sociedade e pelas leis. Ela atribui a prostituição à pobreza ou à falta de caráter das mulheres da alta prostituição. Mas, para ela, a condição de prostituta estava ainda acima da de solteirona "em que há o constrangimento moral da família e da sociedade, além do 'pecado fisiológico'" (MOURA, 1931, p. 32); entretanto, ambas, prostituta e solteirona, eram "igualmente ludibriadas, igualmente desgraçadas, igualmente exploradas, acorrentadas à geena (sic) do capitalismo e dos preconceitos sociais" (MOURA, 1933, p. 23); ambas eram figuras estruturais na sociedade capitalista que não asseguravam o casamento, a maternidade sadia e a hegemonia da mulher burguesa. Para colocar fim a essa exploração ela propunha o amor plural/livre, a maternidade consciente e que as mulheres buscassem a emancipação, se libertassem dos preconceitos, avançando para a conquista de autonomia para as mulheres de todas as camadas sociais. Conforme as mulheres avançassem na libertação, os problemas em sociedade seriam sanados, tal qual a prostituição, "o mercado da carne moça das mulheres". Na obra, Serviço militar para mulher? Recuso-me! Denuncio!, ela afirmou:

E a mulher, a tutela milenar desta civilização unissexual, a criadora de vida, a sensibilidade trucidada pela prepotência masculina, protesta contra a organização sistemática dos meios de destruição do trabalho e dos meios de morte da juventude. [...]

E o seu lema, a divisa da mulher para um mundo melhor - não é a violência do vampirismo social erigido em dogma da Pátria ou do bezerro de ouro.

A nossa divisa é um postulado de humanidade: NEMCARNE FEMININA PARA OSPROSTÍBULOS,

NEM CARNE MASCULINA PARA AS BOCAS DOS CANHÕES (MOURA, 1933, p. 19-21).

Foi neste contexto de embates, de guerras, de misérias e de luxos, que Maria Lacerda e outras feministas da época travaram batalhas pelos direitos das mulheres. Muitas e diferentes foram as frentes de luta: as sufragistas, as libertárias, as comunistas ou mesmo as feministas liberais criaram as bases e levantaram os pilares para a chegada da chamada segunda onda feminista. Muitas delas tornaram-se vegetarianas, como veremos a seguir, por empatia e por entenderem que as outras espécies estavam sendo massacradas pelo avanço científico e industrial e pelos modismos da caça esportiva.

\section{As mulheres vegetarianas}

Em dois livros de Maria Lacerda de Moura encontramos a defesa do vegetarianismo relacionado à libertação humana e, sobretudo, à libertação das mulheres. Em Amai... e não vos multipliqueis (1932) e em Civilização: tronco de escravos (1931) a questão dos animais está relacionada à adoção de uma dieta vegetariana, como também relacionada à luta antivivisseccionista, como veremos adiante. Sobre a alimentação ela escreveu:

No dia em que a mulher se dispuser a libertar-se do jugo do estômago civilizado, passar a comer frutas e legumes, a apagar o fogo doméstico que é o "fogo eterno" do inferno feminino na sua escravidão ao estômago do homem - nesse dia ela recomeçará a sua auto-educação física e mental e iniciará a sua verdadeira libertação humana (MOURA, 1932, p. 233).

O estômago civilizado, como foi nomeado por Maria Lacerda, tratava de hábitos alimentares da burguesia europeia, tomados como modelo em outros locais, sobretudo com o consumo de grandes quantidades de carne de animais de criação, além da caça, que era a demonstração máxima da superioridade humana. O estomago civilizado, era, portanto, dependente do extermínio em massa de outras espécies, o que vinha sendo visto com desconfiança por feministas e anarquistas.

O humanismo havia colocado o homem, macho, branco e eurocêntrico no cume da montanha. Porém, seu progresso político, econômico ou social dependia, em parte, da exploração e da escravização de muitas outras vidas humanas e não humanas. Laura Luedy (2019) escreve sobre a história do abate industrial, sobre o surgimento dos abatedouros e, 
aos poucos, a mudança desses centros de matança em massa para locais cada vez mais isolados e escondidos do mundo civilizado. Diz ela:

A literatura que se debruça sobre o caminho histórico que foi traçado pelas mudanças nas técnicas ocidentais de abate de animais costuma sublinhar algumas linhas comuns que se consolidaram nesse respeito. Destaca-se, sobretudo, o progressivo afastamento espacial dos matadouros em relação aos centros populacionais; as mudanças arquitetônicas que priorizaram os espaços fechados e internamente fragmentados; e as incontáveis mudanças técnicas que terminaram por se traduzir em abatedouros com um número muito maior de trabalhadores que exercem funções mais mediadas por instrumentos, saberes, ritmos que não dominam inteiramente (LUEDY, 2019, p. 76-77).

A morte em grande escala e a produção serializada foram alguns dos alvos da obra lacerdiana, sobretudo a partir de sua chegada a São Paulo e do encontro com a comunidade anarquista em Guararema. ${ }^{10}$ No livro Civilização, tronco de escravos (1931), ela associa, de forma brilhante, a ciência e a industrialização a serviço do poder político e econômico. Para ela, havia uma grande contradição na adoção do termo "civilização", já que os grupos sociais considerados civilizados conjugavam práticas brutais, tais como a caça desportiva e o patriotismo, que eram bases de sustentação das guerras. Outro aspecto relevante é notado em seu debate sobre a produção industrial e o acúmulo de riquezas por uma minoria, graças ao trabalho mal remunerado de uma multidão de trabalhadore/a/s famintos. Já no início da obra, ela aponta as consequências e diz:

É o excesso de produção, sob todos os aspectos, na lavoura como nas indústrias, causa de todos os conflitos na sociedade atual. O nosso mal não vem da falta e sim do excesso de produção. A miséria do mundo moderno ainda vem da fartura e do excesso de riqueza e de progresso material. Da má distribuição de gêneros alimentícios. Por ora, a terra daria bem para a sua população (MOURA, 1931, p. 18).

O acúmulo de riquezas através da produção industrial não resolveu a questão da fome. Muito pelo contrário, agravou as diferenças; o abismo que separa as grandes fortunas da multidão de famintos já era tema presente na obra lacerdiana. Com as outras espécies de animais, o carnivorismo engordou os "estômagos civilizados", porém, não saneou a fome da classe operária, cujo sangue e suor se misturavam nos abatedouros, desde então escondidos, longe dos centros urbanos civilizados e higienizados. Em Pelotas, no Rio Grande do Sul, as charqueadas serviram como fonte de carne de gado para alimentar o povo europeu desde o século anterior, como veremos,

A cidade guarda uma história longa, banhada pelo sangue das charqueadas, ela foi rica para alguns e foi um martírio para outro tanto de pessoas humanas e não-humanas. Durante o século XVIII, a cidade abrigou 40 charqueadas na região conhecida como Tablada, estima-se que nelas cerca de 400/500 vacas e bois eram mortos por ano. O gado era levado pela região dos Pampas e chegava à cidade para ser abatido nas charqueadas, arquitetonicamente, plantadas nas margens do Arroio Pelotas, por onde, em seus $60 \mathrm{~km}$ de extensão, o sangue corria veloz. Neste contexto, o povo negro escravizado sentia o preço do charque na chibata que comia suas carnes e fazia jorrar seu sangue misturado ao dos não-humanos, assim como dos povos indigenas que antes viviam ali ou já haviam sido dizimados ou expulsos de suas aldeias, enquanto a pecuária engordava os bolsos e as panças de poucos, alguns daqui, outros além-mar, sobretudo do povo europeu, que na região estava miscigenado entre portugueses e castelhanos, típico contexto daquela região fronteiriça (BrasilUruguai) (LESSA, 2017, p. 3-4).

No contexto brasileiro os estados do Rio Grande do Sul e de Minas Gerais se destacavam pela criação de gado, e, foi nesse contexto que Lacerda percebeu a distância que separava a produção de carne em larga escala da fome entre as pessoas das classes menos favorecidas, que não tinham o mesmo acesso à produção de carne em escala industrial. Com o avanço das mulheres nas lutas sociais e nos espaços públicos, elas ampliaram o leque de propostas e se sensibilizaram com a grande matança de não humanos, seja na indústria ou na ciência. 
Se os séculos XIX e XX marcaram as lutas das mulheres por direitos, podemos dizer que os séculos $X X$ e $X X I$ viram nascer uma revolução animalista sem precedentes. O avanço nos direitos dos animais coadunou com a expansão do vegetarianismo e, mais recentemente, com a chegada do veganismo. Na obra anarquista Entre colunas, do lusitano Roberto das Neves, ele disserta sobre as relações entre o pensamento libertário e o surgimento de uma revolução na medicina, agregando o vegetarianismo e a macrobiótica ao naturismo. Aspectos ligados aos grupos que migravam para a zona rural em busca de uma nova vida, longe da miséria, da proliferação de doenças, da fome e das guerras (NEVES, 1980). Conforme esse autor,

O vegetarianismo, ou seja, a ausência da carne (por carne entende-se também peixe, aves e ovos) na dieta habitual da maioria dos habitantes da Terra, é antiquissima norma de vida, recomendada pelas mais seguidas religiões e correntes filosóficas. Buda, Lao Tsé, Pitágoras, Platão, Diógenes, Sócrates, Epicteto, Epicuro, Ovidio, Plutarco, Tertuliano, São João, Crisóstomo, São Clemente de Alexandria, Leonardo da Vince, São Francisco de Assis, Cervantes, Spinoza, Descartes, Darwin, Voltaire, Rousseau, Tolstói, Elisée Réclus, Ruskin, Lázaro Luiz Zamenhof, Thoreau, Albert Shweitzer, Albert Einstein, Jean Rostand G. Bernard Shaw, Han Ryner, E. Armand, Maria Lacerda de Moura, Annie Besant, Leadbeater, Krishnamúrti, José Oiticica, Alex Carrel etc., etc., tantos dos mais notáveis homens de todos os tempos, foram ou são vegetarianos. Entre os cristãos, contam-se, além de outros, os Adventistas do Sétimo Dia, que desenvolvem em todo mundo fecunda atividade a favor do vegetarianismo, e as ordens monásticas católicas Trapistas, Cartuxos e Cameldulenses (NEVES, 1980, p. 214).

Roberto das Neves, também vegetariano, mostra nessa obra a relação do vegetarianismo com as práticas libertárias e a busca por uma vida no campo ligada às comunidades libertárias agrícolas, que procuravam afastar-se dos centros urbanos e praticar uma produção de alimentos autossustentável, além de afastar-se das guerras e da industrialização. Se o veganismo é recente na história das relações interespécies, o mesmo não podemos dizer do vegetarianismo como vimos na citação acima.

Em sua obra A politica sexual da carne: a relação entre carnivorismo e a dominância masculina,
Carol Adams (2012) identifica mulheres vegetarianas ligadas às reivindicações feministas. Segundo ela, no século XIX muitas mulheres tornaram-se vegetarianas e escreveram sobre a necessária libertação delas mesmas e das outras espécies. Mulheres como: Agnes Ryan (1878-1954 - EUA); Annie Wood Besant (1847, Inglaterra - 1933, Índia); Clara Barton (1821-1912 - EUA); Elizabeth Cady Stanton (1815-1902 - EUA); Lou Andreas-Salomé (1861, Rússia - 1937, Alemanha) e Matilda Joslyn Gage (1826-1898 - EUA) foram precursoras da alimentação sem carne e da luta contra o uso de animais na ciência e na indústria, sobretudo, na luta antivivisseccionista.

Ao ler a obra de Maria Lacerda (1931), é possivel analisar a sua visão sobre o uso dos animais na ciência e na indústria. Nessa obra ela critica o modelo de apropriação do conhecimento tecnológico e científico pelo capitalismo, principalmente por favorecer o enriquecimento de poucos em detrimento de uma multidão operária mal remunerada. Seguindo a perspectiva anarquista ela percebe a tecnologia e a ciência como potencialmente emancipadoras, porém, apegadas ao modelo capitalista, que sacrifica a vida em nome do progresso social, político e econômico de uma minoria da elite e da aristocracia industrial e ruralista. O progresso socioeconômico de uma minoria internacional seria garantido pela exploração da força de trabalho da massa humana e às custas do sangue de animais não humanos, opressões que ganham espaço na crítica libertária e feminista do final do século XIX e início do século XX.

A relação entre a opressão sexista e especista na literatura feminista libertária, transitou por diferentes abordagens e de variadas formas: crítica à ciência e à vivissecção, crítica à indústria da carne, à instrumentalização dos corpos humanos e não humanos e consequente adoção de uma alimentação vegetariana.

Carol Adams (2012) diz que as mulheres do século XIX viam no vegetarianismo uma libertação da labuta da cozinha, da servidão aos homens e da crença cega no poderio dos médicos, que recomendavam dieta carnista. A crítica à medicina e à ciência tomam forma nos escritos das mulheres 
desde as sufragistas até as feministas libertárias. Para a autora os textos vegetariano-feministas são o referencial ausente da crítica e da história feminista. Ela argumenta a favor da urgência em revisitar os escritos e relacionar os processos de libertação abraçados pelas autoras entre final do século XIX e início do século XX. Diz ainda que é possivel encontrar inúmeras feministas que escreveram sobre o tópico. Carol Adams (2012) sugere revisitarmos os escritos de libertação de autoras do período entre o final do século XIX e o início do século $X X$, e diz, que é possivel encontrar muitas escritoras feministas, libertárias, sufragistas e abolicionistas que publicaram textos importantes sobre o assunto.

A ligação entre a naturalização dos experimentos e a mutilação de animais não humanos, a tortura e a anulação do corpo feminino pelo poder biomédico, são evidências apontadas pelas feministas que mostraram que, desde a era vitoriana, essas práticas formam uma rede de conexões de corpos submetidos aos usos científicos em benefício do capitalismo.

A vivissecção, que é a prática de dissecar o animal vivo, com fins de estudo ou mesmo para testes na indústria, virou preocupação entre mulheres e direcionou seu olhar para as outras espécies, até então vistas de forma meramente instrumental e funcional. Era um enorme coro de antivivisseccionistas pensando e contestando a cruel exploração das outras espécies.

\section{Os mártires da ciência e a luta antivivisseccionista}

André Carvalho e Ricardo Waizbort (2012) escreveram sobre o encontro e o desencontro entre Charles Darwin e Frances Power Cobbe, que se deu no ano de 1868, em que a última estava envolvida em várias causas, como a questão da pobreza, da violência contra as mulheres e na luta contra os excessos cometidos pelos fisiologistas, que através da vivissecção realizavam toda a sorte de experimentos. A prática da vivissecção era crescente com o avanço dos estudos biomédicos, sobretudo por fisiologistas e biólogos; tratava-se da execução de cortar o animal ainda vivo para observar o funcionamento de seus órgãos. Foi somente por volta de 1970 que a prática foi proibida por legislação internacional. Enquanto isso, foram muitas frentes de batalha contra essa forma de morte lenta e extremamente dolorosa. Dizem os autores:

A Inglaterra tem uma longa tradição de pre-
ocupação com a forma como os animais são
tratados. Vários autores do século XVII, tais
como Henry More, Robert Boyle, Robert Hooke,
Joseph Adison, Alexander Pope e outros ques-
tionavam as rinhas de galos e cães, o açula-
mento de ursos, os maus tratos a cães e gatos
de rua e animais de fazenda, e muitas outras
práticas (CARVALHO; WAIZBORT, 2012, p. 357).

Eles ressaltam que havia uma distinção entre os grupos preocupados e os demais, que ainda viam as outras espécies de forma meramente instrumental e funcional. Além disso, a invasão da Índia foi uma das influências marcantes no povo britânico, pois, aquele país colonizado tinha pela vaca uma adoração sagrada. Em 1822 uma lei parlamentar, de autoria de Richard Martin, proibiu o tratamento cruel ao gado. Com uma maior sensibilidade com relação às outras espécies e com a alimentação vegetariana em alta, os testes com animais começaram a ganhar uma implacável ofensiva. Os movimentos antivivissecção, naquele país, datam de meados do século XIX com o surgimento de várias sociedades contrárias a ela, que passaram a pressionar as autoridades no sentido de abolir os experimentos com animais; resultaram dessas pressões a criação, em 1876, do Ato Contra a Crueldade com os Animais, que proibiu a prática na Inglaterra (CUPERSCHMID; CAMPOS, 2007, p. 744). A vivissecção, em alguns aspectos, se tornou um símbolo da opressão industrializada e capitalista sobre os mais fracos e da ação cruel das forças estabelecidas contra a vida.

Maria Lacerda também assumiu posições contrárias à utilização de animais em experimentos aderindo, dessa forma, à luta antivivisseccionista. Essa posição ficou explicita em três capítulos publicados na obra Civilização Tronco de Escravos escritos, possivelmente em 1928, por ocasião da visita ao Brasil do médico fisiologista Serge Voronoff, que veio realizar conferência nas Jornadas Médicas do Rio de Janeiro. 
Serge Samuel Voronoff (1866-1951) nasceu na Rússia e foi naturalizado francês, onde desenvolveu sua carreira de médico fisiologista e professor do Collège de France (LESSA, 2020). Segundo Ethel Cuperschmid e Tarcício Campos (2007, p. 739), Voronoff tornou-se um cirurgião mundialmente famoso "ao fazer enxertos e experiências glandulares para melhoria de raças de ovinos e equinos". Ele defendia que "animais velhos transplantados com testículos de animais mais jovens recuperavam o vigor perdido". A partir das experiências com esses animais, ele desenvolveu uma técnica de xenotransplante, pela qual implantava glândulas sexuais de macacos em homens, aos quais prometia o rejuvenescimento e a restauração física e intelectual. Conforme Cuperschmid e Campos (2007, p. 743) "acompanhando a medicina eugênica em voga nas décadas de 1920 e 1930, o cientista pretendia rejuvenescer organismos humanos com o transplante de glândulas de chimpanzés e babuínos, os quais foram elevados, assim, ao grau de espécies fraternas ao gênero humano". Esses autores informam que, entre 1920 e 1940, a técnica de Voronoff foi utilizada por mais de 45 cirurgiões de vários países, sendo realizados cerca de dois mil xenotransplantes entre primatas não humanos e humanos; somente na França nos anos 1930 mais de quinhentos homens foram operados. Voronoff também realizou experimentos para transplantar ovários de macacas em mulheres, a fim de reduzir os efeitos da menopausa.

A vinda do famoso médico ao Brasil ganhou os noticiários e ocupou por muito tempo o imaginário popular, pois, devido à sua técnica, ele inspirou piadas e marchinhas de carnaval, sendo lembrado, por muito tempo sempre que surgia algum avanço na área médica. Justamente, por meio do "trabalho científico" de Voronoff, Maria Lacerda empreende uma critica à ciência a serviço do capital e à sociedade civilizada. Por um lado, pela busca de milagres para prolongar a vida e a juventude, após esbanjá-la em "gozos materiais"; por outro, pelos meios utilizados para tal, ou seja, a técnica de xenotransplante que consiste em roubar o vigor de uma espécie em benefício de outra, que se considera superior. Ela pergunta:
[...] E vamos buscar, nas florestas, um ser livre e feliz, vivendo em harmonia com as suas necessidades naturaes e o inutilizamos ou matamos. roubamos a sua vitalidade ou reduzimo-la á metade - para resucitar a cadaveres ambulantes, para estimular a senilidades imprestaveis, cujo corpo envelhecido precocemente, talvez em orgias e libertinagens, póde dar vida a filhos predispóstos á mesma degradação moral [...].

É justo que o libertino, o luético, o alcoolatra, o cocainomano, o jogador, o farrista, os "tigres" politicos profissionaes e senis, banqueiros e escroques elegantes, altos funcionarios, senadores e magistrados, intelectuais prostituidos e domesticados, juizes das conciencias alheias... é justo que toda essa massa humana de parasitas e exploradores do rebanho social vá buscar. nas florestas, o animal pujante de seiva de vida - em virtude de sua sobriedade instintiva - e o prenda em ambiente incompativel com a sua liberdade, com os seus hábitos selvagens e o mutile - para rejuvenecer a criaturas de si mesma mutiladas pela vulgaridade ociosa e parasita, pela imbecilidade quintessenciada de prejuizos e rotina, pela baixeza e servilismo, pelo autoritarismo, pelo orgulho da inconciencia de si mesmos? (MOURA, 1931, p. 25, 47).

O historiador norte-americano Peter Sahlins publicou, em 2017, a obra 1668, The year of the animal in France, no qual ele pensa o papel dos animais na construção do absolutismo no reinado de Luís XIV. O ano de 1668 foi o ano da criação de um zoológico no Palácio de Versalhes. Diz o autor: "no zoológico, os animais eram graciosos e civilizados, a fim de representar o poder civilizador do rei, levando à conclusão de que, na natureza animal do humano justificava o governo absolutista" (SAHLINS, 2017, p. 343). A Europa moderna foi marcada pela captura, objetificação e uso de várias espécies de animais para o entretenimento e para a instrumentalização científica e industrial. Não seria sem resistência que as práticas de subserviência das outras espécies iriam persistir. As feministas estavam dispostas a derrubar os cativeiros, fossem eles humanos ou não humanos. Um exemplo disso é um memorial contra o sofrimento dos animais nos laboratórios de ciências, nomeado, o pequeno cão marrom, inaugurado em 15 de setembro de 1906, em Londres, Inglaterra. A estátua tinha uma placa onde se lia: "Em memória do cão terrier marrom levado à morte nos laboratórios da University College, em fevereiro de 1903, depois de ter suportado 
vivissecções por mais de dois meses".11 A prática de realizar experimentações com animais não humanos virou uma febre. Algumas espécies, consideradas biologicamente próximas da humana, foram massacradas, caçadas, presas e torturadas em experimentações que duravam meses. Segundo Cuperschmid e Campos (2007. p. 745), "na década de 1920, foram criados entrepostos comerciais na África Ocidental francesa para armazenar os animais e garantir sua oferta na França". Muitos cientistas tinham seu próprio espaço para estocar e cuidar de seus macacos. Voronoff capturava suas cobaias em territórios da África equatorial que integram os atuais Congo, Sudão, Guiné e Camarões, além de Gibraltar.

As experiências de Voronoff foram interrompidas em razão das pressões da comunidade científica e dos insucessos das suas cirurgias. Para Maria Lacerda, Voronoff representa uma época. Ele nada descobriu e pouco contribuiu para o estudo das secreções glandulares, mas vulgarizou a questão "trazendo-a para o domínio público no sentido de industrializar um assunto de laboratório". De fato, Voronoff que já era rico, aumentou sua fortuna com sua técnica que prometia vitalidade e prolongamento da potência sexual masculina. Sobre as práticas de vivissecção, amplamente utilizadas naquele início de século como já dito, ela escreve:

[...] não compreendo a vivissecção a não ser como um delírio de perversidade inominável, nem chego a ver a vantagem da embriaguez científica que põe milhares de cobaias e cães e qualquer espécie de animal à mercê dos cientistas [...] vaidosos de fazer sofrer os "mártires da ciência" em nome de um principio ou de uma descoberta ou de uma pesquisa ou dos problemáticos benefícios dai resultantes para todo o gênero humano [...]. O homem continuará a descer sempre, bem para baixo de todos os simios, na sua maldade de criatura civilizada, para estimular todas as virulências, desde as guerras até o prazer satânico de martirizar os animais em nome do humanitarismo cínico. [...] A humanidade pode progredir sem a fisiologia, porém, não poderá progredir sem a piedade (MOURA, 1931, p. 32-33).
Ela argumenta que a ciência, submetida aos interesses capitalistas, "ocupa em nosso tempo exatamente o mesmo lugar que o sacerdócio havia ocupado há alguns séculos. [...] escondidos nos títulos, as mesmas castas nas ciências, academias, universidades, congressos" (MOURA, 1931, p. 32-33); e sugere algumas possiveis formas de resistência contra essa situação, como a recusa, por parte da classe trabalhadora, de servir ao sistema, pois, segundo ela: "seria preferivel que o trabalhador se auto amputasse as duas mãos do que optasse por trabalhar em arsenais de guerra, hidroaviões e metralhadoras, navios de guerra e torpedos" (MOURA, 1931, p. 16). Maria Lacerda era uma anarquista pacifista. Nessa fase da sua obra, certamente impactada pelos horrores da primeira grande guerra e em luta contra o avanço do fascismo, ${ }^{12}$ ela se dedicou a escrever sobre a indústria armamentista, um dos pilares da carnificina, e dos testes com animais.

A autora surgiu como uma das vozes da resistência pela positividade da vida. Tanto na frente de batalha contra a guerra quanto em oposição à crueldade perpetrada pela industrialização contra humanos e animais não humanos usados como cobaias. Uma das críticas anarquistas desenvolvida pela autora, foi com relação à ciência moderna em seu posicionamento entre a vida e a produção em escala industrial pois, quando a ciência supervaloriza a razão instrumental, tende a afastar-se da pluralidade da vida para moldar a realidade de acordo com uma imagem abstrata, idealizada e romantizada. A dominação, por ela chamada de "dominismo" estava no centro da discussão. Para ela a vivissecção era um atraso no aperfeiçoamento humano. Escreve:

Não é sentimentalismo piegas e sim pan-humanismo o que lemos em "Atlantida" de 21 de Outubro de 1927, a propósito da vivissecção:

Da perpetração de atos moraes máus não pódem resultar beneficios, de maneira alguma para a humanidade.

A crueldade nunca poderá ser um caminho para o aperfeiçoamento humano.

11 Sobre a Estatua ver em: https://www.magnusmundi.com/pequeno-cao-marrom-memorial-contra-o-sofrimento-dos-animais.

12 Sobre essa fase da obra de Maria Lacerda consultar Leite (1984), Maia e Lessa (2015) e/ou Lessa (2020). 
A ciencia não se adquire com a crueldade. E muito menos a sabedoria, acima de qualquer especie de violencia.

[...] Extirpar uma glandula sexual do macaco, nada representa para o homem, mas, extirpar um testículo do homem é algo de muito importante na sua integralidade...

Quanto a vivisecção, o proprio Claude Bernard, o experimentador "primus inter pares", que massacrou, brutalmente, os dois mil cães e que, sem anestesia, os matou lentamente, o barbaro que, para atender aos protestos da sua vizinhança, cortava antes das experiencias, as cordas vocaes dos animaes, a fim de que não uivassem de dôr. o proprio Claude Bernard diz: "A vivisecção é a deslocação do organismo vivo por meio de instrumentos e de processos que the podem isolar diferentes partes. Reduzida a si mesma, ela só teria alcance restrito, e poderia em certos casos, induzir-nos a erros sobre o verdadeiro papel dos orgãos. Por essas reservas eu não nego a utilidade nem mesmo a necessidade absoluta da vivisecção no estudo dos fenomenos da vida, eu a declaro apenas insuficiente.

Com efeito, nossos instrumentos de vivisecção são tão grosseiros e nossos sentidos, tão imperfeitos que só podemos atingir no organismo as partes grosseiras e complexas.

Não obstante, a mania da vivisecção é o orgulho da ciencia moderna, e as vacinas e soros se multiplicam para gaudio da terapeutica industrializada e para o martírio dantesco das cobaias e dos simios.

Cousa a mais natural do mundo o "homo sapins" roubar do macaco o que seria incapaz de lhe dar, o que dificilmente, excepcionalmente, seria incapaz de dar ao proprio semelhante.

E para que? Se o resultado não passa de sugestão ou se limita à absorpção mais ou menos lenta do hormonio da glandula transplantada?

Resultado para 3 ou 4 annos, findos os quaes, outra enxertia é necessária para novo rejuvenescimento (MOURA, 1931, p. 33-35).

Uma das críticas anarquistas à ciência moderna foi com relação à contradição entre a ciência e a vida, escancarada na ampla utilização da vivissecção, diz a anarquista: "a ciência do vampirismo humano esgotado por senilidade precoce que suga as glândulas de animais" (MOURA, 1931, p. 34). A ideia de civilização, na obra lacerdiana que analisamos aqui, implicava uma contradição entre a capacidade de pensar e de sentir e o abismo entre as pessoas e as outras espécies exploradas pela ciência e pela indústria, cujo discurso central era a promessa de progresso civilizatório.

\section{Considerações finaîs}

Em Maria Lacerda encontramos uma escrita marcada pela positividade da relação humanidade-animalidade em época muito anterior ao início das discussões animalistas, veganas ou ecofeministas. Se ela foi antecipadora de importantes temas da História das Mulheres e das lutas feministas, como já demonstram os estudos sobre sua obra, ela foi também uma visionária ao expectar relações de exploração dos humanos sobre as outras espécies. Ela buscou novos campos para pensar e agir além de uma nova forma de fazer ciência, através das artes e das relações com os animais. As narrativas do passado iluminam e constroem histórias das relações interespécies. Os textos libertários de Maria Lacerda de Moura são narrativas de resistências feministas, repletos de deslocamentos e ressignificações, escritos em um momento de profunda transformação socioeconômica e cultural. Seus escritos estavam em diálogo com um pensamento anarquista internacional que questionava a ideia de progresso prometido no processo de constituição e de difusão massificada da ciência e da tecnologia.

A ciência e a tecnologia teriam utilidade e proporcionariam bem-estar social, em uma sociedade utópica, onde a propriedade coletiva dos meios de produção e a emancipação feminina prevalecessem e a aglomeração das cidades, consideradas um locus para a aplicação da ciência e da tecnologia, fosse adequada para uma integração orgânica com a natureza através do trabalho rural coletivo. Eis uma das propostas de Maria Lacerda de Moura, proposta essa que também antecipa algumas das lutas ecológicas e ecofeministas ${ }^{13}$ que surgiram muitas décadas depois.

A partir das críticas de Maria Lacerda de Moura podemos perceber que o tratamento dado aos animais não humanos define muito quem somos e o tipo de sociedade na qual vivemos. O respeito às outras espécies pode ser o início de uma transformação na vida planetária, na relação humanidade-animalidade-plantas, para

13 O ecofeminismo é uma prática social que interseccionaliza as questões ecológicas ao pensamento, teorização e ação feminista. Existem muitas vertentes e teorias, neste texto trabalhamos com o pensamento ecofeminista na vertente de Carol Adams (2012). 
avançarmos em direção aos modos de existência mais afetivos e criativos. E a aplicação do conceito de ciência, pode assim estar mais comprometida com os valores da vida criativa. A empatia e o amor interespécies significa pensar que as outras formas de vidas importam, que nos modificam e que criam formas de convivio.

\section{Referências}

ADAMS, Carol. A politica sexual da carne: a relação entre carnivorismo e a dominância masculina. Tradução de Cristina Cupertino. São Paulo: Alaúde, 2012.

CARVALHO, André L. L:; WAIZBORT, Ricardo. Os mártires de Bernard: a sensibilidade do animal experimental como dilema ético do darwinismo na Inglaterra vitoriana. Science Studies, São Paulo, v. 10, n. 2, 2012. Disponivel em: http://www.scielo.br/scielo.php? scrip$\mathrm{t}=$ sci_arttext\&pid=S1678-31662012000200007. Acesso em: 11 nov. 2019. CORREIO DA MANHÃ. Rio de Janeiro: Civilização Brasileira Editora, 13 set. 1931.

CUPERSCHMID, Ethel Mizrahy; CAMPOS, Tarcisio Passos Ribeiro de. Os curiosos xenoimplantes glandulares do doutor Voronoff. História, Ciências, Saúde - Manguinhos, Rio de Janeiro, v. 14, n. 3, p. 737-760, jul./set. 2007.

HUBBARD, Ruth. Algumas ideias sobre a masculinidade nas ciências naturais. In: GERGEN, Mary Mc Canney (org.). O pensamento feminista e a estrutura do conhecimento. Rio de Janeiro: Rosa dos Tempos: EDUNB, 1993. p. 21-36.

LEITE, Miriam Lifchitz Moreira. Maria Lacerda de Moura: uma feminista utópica. Florianópolis: Editora Mulheres, 2005.

LEITE, Miriam Lifchitz Moreira. Outra face do feminismo: Maria Lacerda de Moura. São Paulo: Ática, 1984.

LESSA, Patricia. Amor \& Libertação em Maria Lacerda de Moura. São Paulo: Entremares, 2020.

LESSA, Patrícia. A política educacional para a sexualidade e o papel das mulheres na ciência brasileira. In: MAIA, Jorge Sobral da Silva; BIANCON, Mateus Luiz. Educação das relações de gênero e em sexualidade: reflexões contemporâneas. Curitiba: Appris, 2014, p. 71-82.

LESSA, Patrícia. A zoopoética e o pensamento ecosófico para narrar a vida dos animais. In: SEMINÁRIO INTERNACIONAL FAZENDO GÊNERO, 11; WOMEN'S WORLDS CONGRESS, 13., 2017. Florianópolis. Anais [...]. Florianópolis: UFSC, 2017. p. 1-13. Disponivel em: http://www.wwc2017.eventos.dype.com.br/resources/ anais/1503857206_ARQUIVO_ArtigoFGLessaCorrigido. pdf. Acesso em: 4 dez. 2019.

LIMA, Nabylla Fiori de. Maria Lacerda de Moura na revista Estudios (1930-1936): anarquismo individualista e filosofia da natureza. 2016. 167 f. Dissertação (Mestrado na linha Tecnologia do Trabalho) - Programa de Pós-Graduação em Tecnologia, Universidade Federal Tecnologica do Paraná, Curitiba, 2016. Disponivel em: http://repositorio.utfpr.edu.br/jspui/bitstream/1/1993/1/CT_PPGTE_M_Lima\%2C\%20Nabylla\%20 Fiori_2016.pdf. Acesso em: 8 nov. 2019.
LUEDY, Laura. Mercadoria e signo: notas sobre o abate industrial no Brasil hoje e alguns de seus marcadores expressivos. In: LESSA, Patricia; STUBS, Roberta; BELLINI, Marta. Relações interseccionais em rede: feminismos, veganismos, animalismos. Salvador: Devires, 2019. p. 68-94.

MAIA, Claudia; LESSA, Patrícia. Maria Lacerda de Moura: crítica à familia burguesa e à exploração feminina. In: MAIA, Claudia; PUGA, Vera. História das Mulheres e do Gênero em Minas Gerais. Ilha de Santa Catarina: Editora Mulheres, 2015. p. 97-121.

MOURA, Maria Lacerda. Amai e ... não vos multipliqueis Rio de Janeiro: Civilização Brasileira, 1932.

MOURA, Maria Lacerda de. Civilização, tronco de escravos. Rio de Janeiro: Civilização Brasileira, 1931.

MOURA, Maria Lacerda de. Autobiografia. In: LEITE, M. L. M. (org.). Maria Lacerda de Moura: uma feminista utópica. Florianópolis: Ed. Mulheres; Santa Cruz do Sul: Edunisc, 2005. p. 36-46.

MOURA, Maria Lacerda de. Serviço militar obrigatório para mulher? Recuso-me! Denuncio! 3. ed. [S. I.]: Opúsculo Libertário, 1999.

MOURA, Maria Lacerda de. Renovação. In: GONÇALVES, Adelaide; BUNO, Allyson; QUEIROZ, Camila (org.). Renovação. Fortaleza: Edições UFC, 2015. Edição fac-simile.

NEVES, Roberto das. Entre colunas. Rio de Janeiro: Germinal, 1980 .

FANNY Bernard: uma voz antivivisseccionista no século XIX. Olhar animal, São Paulo, 11 fev. 2014. Disponivel em: https://olharanimal.org/fanny-bernard-uma-voz-antivivisseccionista-no-seculo-xix. Acesso em: 11 nov. 2019.

PEDRO, Joana M. Relações de gênero como categoria transversal na historiografia contemporânea. Topoi, Rio de Janeiro, v. 12, n. 22, p. 270-283, jan./jun. 2011.

RAGO, Margareth. Amores lícitos e ilícitos na modernidade paulistana ou no bordel de Madame Pomméry. Teoria \& Pesquisa, São Carlos, n. 47, p. 93-118, jul./dez. 2005.

RAGO, Margareth. Anarquismo e feminismo no Brasil. Audácia de sonhar: memória e subjetividade em Luce Fabbri. 2. ed. Rio de Janeiro: Achiamé, 2007.

RAGO, Margareth. Entre o anarquismo e o feminismo: Maria Lacerda de Moura e Luce Fabbri. Verve Revista do Núcleo de Sociabilidade Libertária Pepgcs, São Paulo v. 21, p. 54-77, 2012

RODRIGUES, Edgar. Os Libertários. Rio de Janeiro: VJR Editores Associados, 1993.

SAHLINS, Peter. 1668: the year of the animal in France. New York: Zone Books, 2017.

SOIHET, R. O feminismo tático de Bertha Lutz. Florianópolis: Editora Mulheres; Santa Cruz do Sul: EDUNISC, 2006.

\section{Patrícia Lessa}

Doutora em História pela Universidade de Brasilia (UnB), em Brasília, DF, Brasil; professora da Universidade Estadual de Maringá (UEM), em Maringá, PR, Brasil. 


\section{Cláudia Maía}

Pós-doutora em História pela Universidade Nova de Lisboa (UNL), em Lisboa, Portugal; doutora em História pela Universidade de Brasilia (UnB), em Brasília, DF,

Brasil; professora da Universidade Estadual de Montes Claros (Unimontes), em Montes Claros, MG, Brasil.

\section{Endereço para correspondência}

\section{Patrícia Lessa}

Universidade Estadual de Maringá

Av. Colombo 5790, DFE, Bloco I-12

8720270

Maringá, PR, Brasil

\section{Cláudia Maia}

Rua Serra Vermelha, 165

Morada da Serra, 39401780

Montes Claros, MG, Brasil 